\title{
THE EFFECT OF DRY-WET CYCLE ON CRACK PROPAGATION AND SHEAR STRENGTH INDEX OF YUNNAN LATERITE IN CHINA
}

\author{
ZHU, W.-W. \\ School of Urban and Rural Construction \& Engineering Management, Kunming University \\ No. 2 Puxin Road, Kunming Economic Development Zone, Yunnan Province, China \\ (e-mail: zwwswfc@126.com; phone: +86-158-1202-5370; fax: +86-871-6509-8321)
}

(Received 23 $3^{\text {rd }}$ Feb 2019; accepted $3^{\text {rd }}$ May 2019)

\begin{abstract}
To understand the changing pattern of crack propagation and shear strength index of Yunnan laterite in China after dry-wet cycle, prepared the Yunnan laterite with certain moisture content and made the soil cake samples after compaction which underwent indoor spraying and air dry to simulate the drywet cycle caused by multiple precipitation and evaporation in the project, and the determination of crack width and direct shear test were carried out for samples with various numbers of cycles. The results indicated that the crack process of Yunnan laterite could be classified into three stages upon dry-wet cycle: crack developmental stage, crack progression stage and crack stable stage. The cohesion and internal friction angle of the samples were reduced as the crack propagation of continued, with the reduction amplitude of cohesion greater than that of the internal friction angle, and the reduction law of both in line with the logistic curve pattern.
\end{abstract}

Keywords: Yunnan laterite, dry-wet cycle, shrinkage, crack width, shear strength

\section{Introduction}

Yunnan is one of the most developed areas of laterite in China. Laterite is a red color-based soil formed by weathering, micro-agglomeration and soil-forming processes of iron-rich mother rocks in hot and humid climates (Huang et al., 1998). Yunnan laterite is a special kind of clay, showing the characteristics of high clay content, high liquid limit, large natural porosity ratio, low permeability coefficient, high dispersivity, weak expansibility and strong shrinkage (Liu et al., 2005). Due to the little knowledge of the basic properties of Yunnan laterite, quite a few engineering disasters related to laterite have occurred in Yunnan Province. For example, the development of shrinkage cracks in lateritic foundation led to the settlement of buildings caused by strength reduction, and mining groundwater resulted in the shrinkage and cracking of red soil slope, strength reduction, and landslides after rainfall.

Yunnan, a region with slow economic development in China, is faced with quite a lot of laterite problems with the commencement of a large number of railway and highway projects. At present, the study on Yunnan laterite is mainly focused on the basic physical and mechanical properties index (Huang et al., 1998; Liu et al., 2005; Yuan, 2002; He et al., 2008), chemical composition (Huang, 2002), and the effect of rainfall scouring laterite slope on its physical and chemical properties (Zhang et al., 2016). The study on the cracking mechanism of soils under dry-wet cycles is mainly concentrated in common clay (Sun et al., 2015; He et al., 2012; Rayhani et al., 2007, 2008) and expansive soils (Tang et al., 2011, 2012, 2013), and the engineering properties of Yunnan laterite are different from those of the two types of soil. The objective of this study is to understand the changing pattern of crack propagation and shear strength index of Yunnan laterite. The present study directly reflected the occurrence and expansion of cracks in Yunnan laterite during the dry-wet cycle by indoor simulating 
the reciprocating process of natural rainfall and evaporation and revealed that the decrease of laterite strength was caused by the occurrence and expansion of cracks. In this paper, an empirical formula reflecting the decrease in the shear strength index of Yunnan laterite with the increase in the number of dry-wet cycles, and the mechanism of the occurrence and propagation of cracks in Yunnan laterite after dry-wet cycles was also discussed.

\section{Experiment schemes}

The soil material was excavated from Luoyang Section of East Ring Expressway in Kunming on September 2. The excavation amount was about $80 \mathrm{~kg}$. Yunnan laterite soil with the certain moisture content was prepared and compacted according to the heavyduty II-1 standard (Ministry of Communications of the People's Republic of China, 2007), which was used to make soil cake samples. To stimulate the state of laterite after experiencing rainfall and evaporation cycles in nature, multiple dry-wet cycles were performed indoors to create cracks and expansion. The change pattern of cracks during dry-wet cycles was observed morphologically, and the maximum crack width and saturated shear strength index were determined after experiencing various numbers of dry-wet cycles. Shear strength index was measured by direct fast shear test.

The selected laterite was brown in dry and red brown after immersion with the clay particles of $41.25 \%$, the granule particles of $47.93 \%$ and the sand particles of $10.82 \%$, whose basic physical and mechanical properties were shown in Table 1. Using standard compaction test, the maximum dry density $\left(\rho_{d \max }\right)$ and the optimal water content $\left(\omega_{o p}\right)$ were determined as $1.62 \mathrm{~g} / \mathrm{cm}^{3}$ and $17.8 \%$, respectively.

Table 1. Basic physical and mechanical properties of lateritic soil

\begin{tabular}{c|c|c|c|c|c}
\hline $\begin{array}{c}\text { Natural wet } \\
\text { density } \\
\rho\left(\mathrm{g} / \mathrm{cm}^{3}\right)\end{array}$ & $\begin{array}{c}\text { Specific density of } \\
\text { solid particles } \\
G_{s}\end{array}$ & $\begin{array}{c}\text { Natural } \\
\text { moisture content } \\
\omega(\%)\end{array}$ & $\begin{array}{c}\text { Liquid limit } \\
\omega_{L}(\%)\end{array}$ & $\begin{array}{c}\text { Plastic limit } \\
\omega_{P}(\%)\end{array}$ & $\begin{array}{c}\text { Plasticity } \\
\text { index } \\
I_{P}\end{array}$ \\
\hline 1.76 & 2.64 & 29.2 & 52.0 & 28.0 & 25.0 \\
\hline
\end{tabular}

In this experiment, the soil was prepared according to moisture content $\omega=21 \%$, and the prepared soil was sealed in plastic bags for 24 hours to ensure the uniform moisture content. The samples were then placed in the compaction cylinders (inner diameter of $100 \mathrm{~mm}$ and height of $127 \mathrm{~mm}$ ) to compact, and the soil moisture content $\omega$, dry density $\rho_{d}$ and the compaction coefficient were $20.8 \%, 1.53 \mathrm{~g} / \mathrm{cm}^{3}$ and $94.4 \%$, respectively. The soil in the compaction cylinder was slowly lifted by a jack, and the soil cake with the thickness of $20 \mathrm{~mm}$ was obtained by carefully cutting with a wire saw, using which a total of 72 samples were prepared. The 72 samples were divided into 9 groups with 8 in each group, and the dry-wet cycles of $0,1,2,3,4,5,6,7$ and 8 were carried out. A small portion of the soil cake was collected via using small ring knife (inner diameter of $61.8 \mathrm{~cm}$ and height of $20 \mathrm{~mm}$ ) to determine the shear strength index.

The dry and wet in the cycles of the present study were not absolute dry and wet, but the stimulation of the humidification and dehumidification process of Yunnan laterite in nature. The control standard of "dry" was air dry of the soil cake in the lab for $48 \mathrm{~h}$. The standard of "wet" was: (1) spraying the surface of samples by using a syringe with needle (with the distance from needle tip to sample surface of $1 \mathrm{~cm}$ and the spraying 
rate of $0.5 \mathrm{ml} / \mathrm{s}$ ) until the surface was covered in water. Spray was continued after water was absorbed by samples until the water stayed at the same level after $5 \mathrm{~min}$; or (2) spray was conducted until free water seeped from the bottom of the sample if the water sprayed to the sample surface was always absorbed completely within $5 \mathrm{~min}$.

The experiment was performed in October in Kunming in which the minimum night temperature, the maximum day temperature and relative humidity were $12{ }^{\circ} \mathrm{C}, 26^{\circ} \mathrm{C}$ and $43-58 \%$, respectively.

\section{Results and analysis}

The surface cracks of Yunnan laterite samples were clearly visible after various cycles of dry-wet cycles. The expansion status of the cracks after 1, 2, 3, 4, 5 and 6 drywet cycles were as shown in Figure 1. Almost all the samples showed the development of annular microfracture after the first dry-wet cycle, and some samples showed a relatively wide crack during the first air dry process, which might be due to the weak structural plane resulted from the unequal stress during the sample preparation, so the cracks were formed during the first air dry process because of the uneven contraction distortion after dehydration. After multiple dry-wet cycles, the crack width was gradually increased and secondary cracks were formed. The initial annular crack gradually radiated to the periphery, and the maximum crack width reached the scale of millimeter after the fourth dry-wet cycle. The cracks expansion tended to be stable and the width was no longer increased after the sixth cycle. With the $100 \mathrm{x}$ visualizer of crack width (1 DIV/0.02 mm, Shangyu Jingnuo Instrument Factory, Zhejiang Province, China; Fig. 2), the maximum crack width after various numbers was determined which was shown in Figure 3.

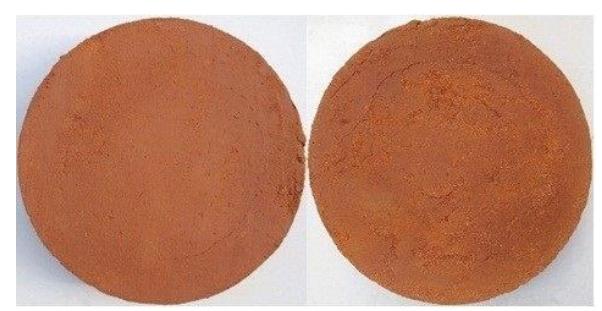

(a) after the $1^{\text {st }}$ dry-wet cycle $\quad$ (b) after the $2^{\text {nd }}$ dry-wet cycle

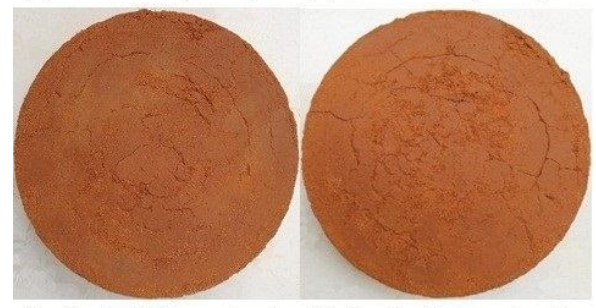

(c) after the $3^{\text {rd }}$ dry-wet cycle $\quad$ (d) after the $4^{\text {th }}$ dry-wet cycle

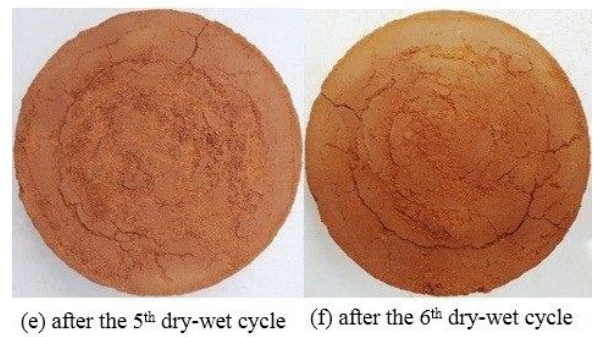

Figure 1. The crack expansion in soil samples after dry-wet cycle 


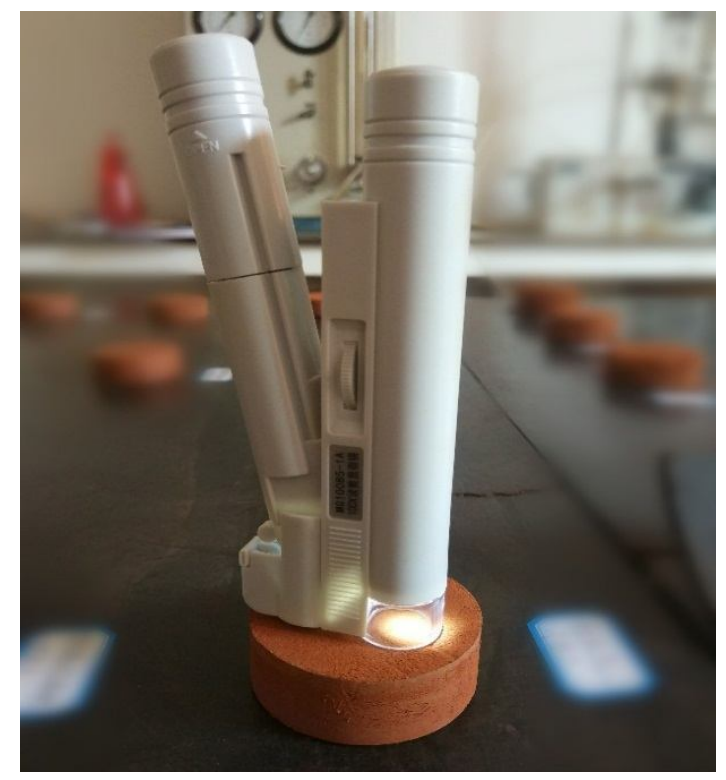

Figure 2. The visualizer of crack width (100x)

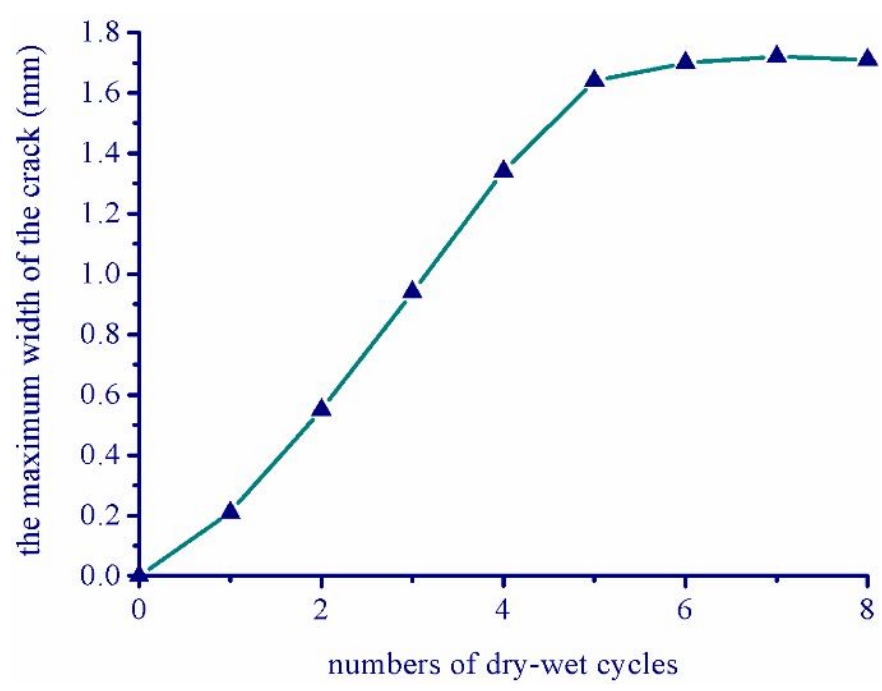

Figure 3. The maximum crack width after dry-wet cycles

Although the propagation of cracks is one of the contents of this study, for road engineering, more attention is paid to the shear strength attenuation of soil caused by cracks. The variation of soil moisture content during rainfall or evaporation in nature is not as dramatic as that of water saturation or oven drying. Therefore, the shear test was performed after each dry-wet cycle, and such shear strength index could reflect the effect of the crack development process on the strength of Yunnan laterite after the expansion-contraction cycle due to the dry-wet cycles caused by the external climate. The relationship of cohesive strength $(c)$ and internal friction angle $(\varphi)$ to the numbers of dry-wet cycles was as shown in Figure 4. Cohesion and internal friction angle are two indexes of shear strength of soil. Cohesion is the mutual attraction between the adjacent parts of the soil. This mutual attraction is the expression of the molecular force between the molecules of the same substance. cohesion is also the shear strength of the 
failure surface without any positive stress. The internal friction angle reflects the friction characteristics of soil, including the sliding friction caused by the rough surface of particles and the occlusal friction caused by the embedding, interlocking and disengaging of particles.

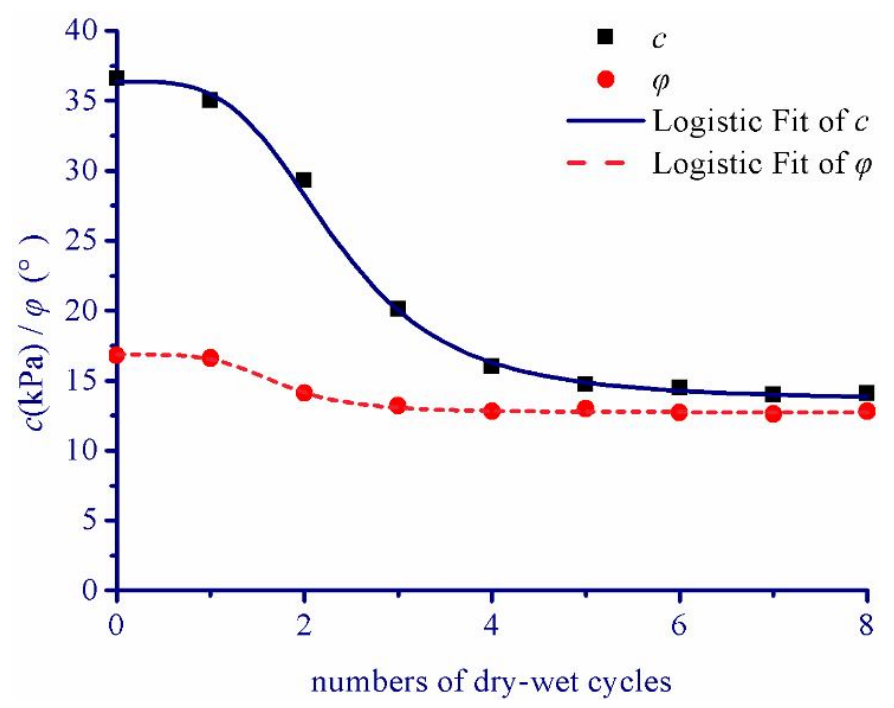

Figure 4. The relationship of cohesive strength (c) and internal friction angle $(\varphi)$ to the numbers of dry-wet cycles

The results indicated that as the cycle increased, the cracks were formed from scratch and became larger, leading to the damage in the integrity of the soil and the gradual strength reduction of Yunnan laterite, which is consistent with the general knowledge of the variation pattern of shear strength in clay soil. Among these, the change in cohesive strength was most significant, which only retained $40 \%$ of its initial value after 5 cycles. Cohesion took on the trend of constant reduction due to successive crack development. Although some small cracks might close or partially close during humidification, the scars still existed, and the gradual increase in such damage of soil integrity resulted in looser soil and lowered strength. However, crack propagation followed the basic rule of being fast then slow, thus, the change to the number of dry-wet cycles of cohesion showed a form of being steep and then gentle as a whole. The internal friction angle of Yunnan laterite also decreased, but the altitude was much smaller than that of cohesive strength, showing $77 \%$ of the initial value after five dry-wet cycles. On one hand, the existence of cracks in the soil allowed Yunnan laterite to become fragmented. Furthermore, the expansion and shrinkage deformation led to loosen soil and reduced compactness, which tended to be stable after five cycles. Therefore, the decrease of internal friction angle at the beginning of dry-wet cycles might be related to the decrease of soil density caused by expansion and contraction.

Cracks lead to the decrease or lose of the cementation force between soil particles. Therefore, cohesion is significantly reduced, the further impact of crack propagation on it is not significant, and the main factor affecting the internal friction angle is the property of soil particles. Compared with cohesive strength, the reduction of internal friction angle entered stable stage with minimal variation.

Experiments revealed the expansion of cracks with increasing the numbers of drywet cycles, and the process of crack expansion was generally consistent with the 
reduction in the strength of Yunnan laterite, and it was shown that the strength reduction was resulted from the crack propagation.

The relationship of cohesive strength $c$ and internal friction angle $\varphi$ to dry-wet cycle number exhibited inversed S-shape curve (Fig. 4), and it could be fitted via using the mathematical expression of logistic curve, which were:

$$
\begin{gathered}
c=\frac{A_{1}-A_{2}}{1+\left(n / n_{1}\right)^{p}}+A_{2} \\
\varphi=\frac{A_{3}-A_{4}}{1+\left(n_{1} / n_{2}\right)^{g}}+A_{4}
\end{gathered}
$$

In Equations 1 and 2, $n$ is the number of dry-wet cycles; $A_{1}, A_{2}, A_{3}, A_{4}, n_{1}$ and $n_{2}$ indicate the fitting parameters.

The above formula, as an empirical formula reflecting the rule that the shear strength index of Yunnan laterite is reduced with the increase in the number of dry-wet cycles, can be used to estimate the final value of shear strength index of laterite under the longterm action of sunshine and rain. The fitting results of the present study were as follows:

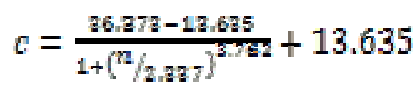

$$
\begin{aligned}
& \varphi=\frac{16,854-12.745}{1+(1 / 1.775)^{4.45} 7}+12.745
\end{aligned}
$$

Calculated by Equations 3 and 4, the ultimate reduction value of the shear strength of the laterite as the cycle numbers increased were $c=13.635 \mathrm{kPa}$ and $\varphi=12.745^{\circ}$. The cohesive strength and internal friction angle were reduced to $37 \%$ and $76 \%$ of the initial value, respectively.

The simplified Bishop method is a quantitative analysis method for the stability of subgrade slope. The basic principle is: assuming that the slope has an arc sliding surface, the slope stability factor can be calculated by comparing the sliding moment produced by the sliding surface with the sliding moment produced by the sliding body. When calculating, the stability coefficient $K$ is assumed first, and then the calculated value $F_{S}$ of the stability coefficient is inversely calculated. Then the assumed value $K$ is adjusted according to the calculated value $F_{S}$ of the stability coefficient, and the relative error between $K$ and $F_{S}$ is repeated until the relative error between $K$ and $F_{S}$ is within the prescribed range. To intuitively demonstrate the effect of the decrease in the shear strength of Yunnan laterite caused by dry and wet cycles on the slope stability, the stability coefficient $F_{S}$ was calculated (simplified Bishop method) for the homogeneous embankment (soil bulk density of $18.5 \mathrm{kN} / \mathrm{m}^{3}$ ) with the height of $10 \mathrm{~m}$, the width of $20 \mathrm{~m}$ and the slope ratio of 1:1 using the strength index obtained in the test, which was shown in Figure 5.

\section{Discussion}

According to the data, the developmental process of cracks in the Yunnan laterite samples upon dry-wet cycles can be classified into 3 stages: crack developmental stage, crack progression stage and crack stable stage. 


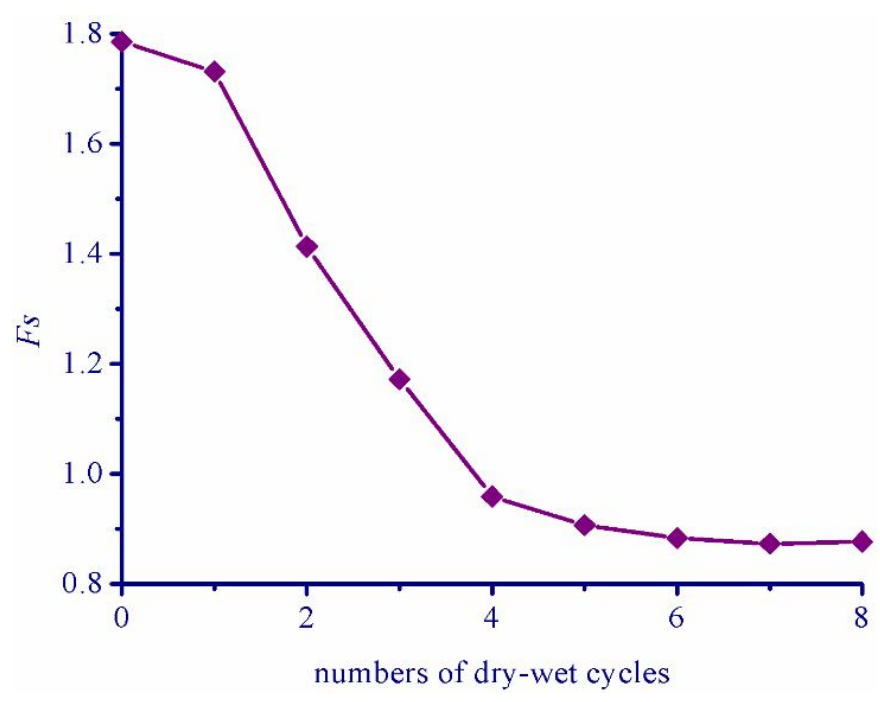

Figure 5. The relationship of safety factor $\left(F_{S}\right)$ and numbers of dry-wet cycles

(1) Crack developmental stage. The first dry-wet cycle is the crack developmental stage. During this process, humidification of laterite samples occurs only in the original pores, the effect of humidification only lies in enabling the laterite to absorb water, and the effect of dehumidification only lies in emigration of partial moisture in the pores. However, such dry-wet cycle results in moisture gradient in laterite samples, and a large amount of moisture in the samples softens the connection between laterite particles, leading to the formation of micro-cracks in the samples, which creates favorable conditions for further expansion cracking and shrinkage cracking during later dehumidification. In the present study, the dry density of laterite sample was relatively high, so the swelling force caused in the process of humidification was also large, and the micro-cracks were produced after the first dry-wet cycle. It has been demonstrated that cracks were hard to form in the samples with relatively low dry density (Zhao et al., 2017).

(2) Crack progression stage. The $2^{\text {nd }}-5^{\text {th }}$ cycle is the crack progression stage. After the $1^{\text {st }}$ dry-wet cycle, the main effect of water absorption and humidification of laterite sample is to increase the thickness of water film between laterite particles, resulting in the swelling and cracking of laterite sample. The main effect of dehumidification is to reduce the thickness of water film between laterite particles, resulting in shrinkage and cracking of laterite samples, so the micro-cracks gradually develop into macro-cracks. With increasing the cycles, the thickness of water film among soil particles further increases, and the swelling and cracking laterite become more significant. During this development stage, the originally formed cracks have been further deepened and widened, and crack propagation has been achieved. In this process, crack propagation comes with the decrease in the shear strength index.

(3) Crack stable stage. Cycle beyond the $6^{\text {th }}$ is crack stable stage. During such a process, the main effect of water absorption and humidification of laterite sample is not to increase the thickness of water film between laterite particles and cause expansion cracking, but to fill the existing cracks, and the main function of dehumidification is to reduce moisture between laterite particles in existing fractures. Due to the large crack width and high moisture content, there is no water loss, shrinkage and crack deepening in a short time, which is not enough to form new cracks, so the expansion of cracks 
enters into a stable stage. In the repeated dry-wet cycles, the cracks are opened, closed and propagated under the combined effect of expansion and shrinkage, and they gradually reach a stable state after certain cycles. During this process, the attenuation of shear strength index in the soil samples also entered a stable period.

Although there are still some unreasonable factors in the method employed here, such as the artificial disturbance in sample preparation, the small size of sample, and the discrepancy between the simulated humidification and dehumidification and natural process, such a method is still preferable considering the difficulties in the present study on the cracking and strength of Yunnan laterite. Such a method makes it possible to study the crack initiation and propagation in Yunnan laterite caused by dry-wet cycles and the effect pattern of crack propagation on its strength by conventional geotechnical instruments, which provides a reasonable and effective basis for the analysis of laterite engineering problems in Yunnan. In the present study, the dry density of laterite sample was relatively high, and its compaction coefficient was similar to that of embankment. Therefore, the process of cracking during dry-wet cycles and the attenuation process of shear strength index are representative.

\section{Conclusion and suggestion}

(1) With a reasonable and simple experimental procedure, determined the crack width of Yunnan laterite and the variation pattern of shear strength index as the cracks expanded during dry-wet cycles. The data showed the phenomenon of the occurrence and expansion of cracks in Yunnan laterite upon dry-wet cycles, and revealed that the reduction in the strength of laterite was resulted from the occurrence and expansion of such cracks.

(2) The results indicated that either cohesive strength or internal friction angle exhibited certain decrease with the propagation of cracks which had a stronger effect on cohesive strength. An empirical formula was also presented showing the decrease of shear strength index of Yunnan laterite with the increase of dry-wet cycles as well as the development of cracks. Such a formula can be used to estimate the ultimate strength index of dense Yunnan laterite under long-term sunshine and rain.

(3) The mechanism of occurrence and expansion of Yunnan laterite after dry-wet cycles was discussed. During the crack developmental stage, the wetting process softens the connection between laterite particles, leading to the formation of microfractures after drying. During the crack expansion stage, the wetting process increases the thickness of water film between laterite particles to cause crack expansion of samples, whereas the drying process reduces the water film thickness between particles resulting in the shrinkage and cracking, and the micro-cracks gradually develop into macrocracks. During the crack stable stage, because of the large width of cracks, the wetting process is to fill the cracks. The moisture content is relatively high during this stage, shrinkage and deepened cracks due to dehydration will not occur in a short time, and water loss is not enough to rip soil and form new cracks.

(4) In the future, investigations are needed to understand the pattern of crack propagation and strength attenuation of Yunnan laterite under various regulated conditions of dry-wet cycle and large-sized samples. For the foundation, embankment or slope of Yunnan laterite, more attention should be paid to the crack formation and strength degradation caused by rainfall and drought, especially with the large gradient of moisture content and uneven expansion. Because the effect of crack on the cohesive 
strength is more significant, the value of clay cohesive strength should be cautiously identified in engineering design, and the uniform moisture content is desired in the actual projects with Yunnan laterite.

Acknowledgements. This research was funded by Yunnan Applied Basic Research Projects (2016FD108).

\section{REFERENCES}

[1] He, J., Wan, J., Wang, Y. (2012): Desiccation cracks and hydraulic performance of compacted clay liner via laboratory wet-dry cycling tests. - Journal of Engineering Geology 20(3): 397-402.

[2] He, X. M., Su, H., Yan, H. H. et al. (2008): Study on engineering properties of red clay at Kunming New International Airport. - Yangtze River 39(24): 49-52.

[3] Huang, Y., Fu, B. C. (1998): Research on laterization and specific property of laterite in engineering geology. - Chinese Journal of Geotechnical Engineering 20(3): 40-44.

[4] Huang, Y., Fu, B. C. (2002): The change properties of the chemical compositions for laterite. - Journal of Kunming University of Science and Technology 27(4): 63-70.

[5] Liu, Z. B. (2005): Engineering characteristics and geotechnical engineering problems of Yunnan red clay. - Yunnan Electric Power 33(4): 44-47.

[6] Ministry of Communications of the People's Republic of China. (2007): Test Methods of Soils for Highway Engineering. - JTG E40-2007.

[7] Rayhani, M. H., Yanful, E. K., Fakher, A. (2007): Desiccation-induced cracking and its effect on the hydraulic conductivity of clayey soils from Iran. - Canadian Geotechnical Journal 44(3): 276-283.

[8] Rayhani, M. H. T., Yanful, E. K., Fakher, A. (2008): Physical modeling of desiccation cracking in plastic soils. - Engineering Geology 97(1): 25-31.

[9] Sun, D. A., Huang, D. J. (2015): Soil-water and deformation characteristics of Nanyang expansive soil after wetting-drying cycles. - Rock and Soil Mechanics 36(S1): 115-119.

[10] Tang, C. S., Shi, B., Liu, C., Suo, W. B., Gao, L. (2011): Experimental characterization of shrinkage and desiccation cracking in thin clay layer. - Applied Clay Science 52(1): 69-77.

[11] Tang, C. S., Cui, Y. J., Tang, A. M., Shi, B. (2012): Shrinkage and desiccation cracking process of expansive soil and its temperature-dependent behaviour. - Chinese Journal of Geotechnical Engineering 4(12): 2181-2187.

[12] Tang, C. S., Wang, D. Y., Shi, B., Liu, C. (2013): Quantitative analysis of soil desiccation crack network. - Chinese Journal of Geotechnical Engineering 35(12): 2298-2305.

[13] Yuan, X. (2002): Engineering property and its application of red clay in Yunnan. Journal of Nanchang College of Water Conservancy and Hydroelectric Power 21(1): 5962.

[14] Zhang, Z. L., Hong, B., Huang, Y. et al. (2016): Impact of physical chemical properties and the erosion on the slope of the Yunnan laterite under rainfall conditions. - Journal of Water and Soil Conservation 30(3): 6-18.

[15] Zhao, G. G., Huang, Y., Zhang, J. F. et al. (2017): Investigation on the development of cracks of laterite of Yunnan under wetting-drying cycles. - Journal of Soil and Water Conservation 31(2): 157-165. 